\title{
Diagnosing familial hypercholesterolaemia in childhood by measuring serum cholesterol
}

\author{
J V LEONARD, A G L WHITELAW, O H WOLFF, J K LLOYD, J SLACK
}

As the treatment of children with familial hypercholesterolaemia will have to be life long and current regimens are difficult to sustain, ${ }^{5}$ it is important to understand the degree of certainty with which the diagnosis can be made. We examined

\section{Summary}

The serum cholesterol concentrations of 134 children aged 1-16 years who had at least one first-degree relative with presumed familial hypercholesterolaemia showed a bimodal distribution, and, using the maximum likelihood technique, two overlapping curves could be fitted. The mean value of the affected children (heterozygotes) was $8.9 \mathrm{mmol} / 1$ and that of the unaffected $4.9 \mathrm{mmol} / 1$. The two curves intersected at $6.77 \mathrm{mmol} / 1$, and at this point $5 \%$ of the unaffected children had values over $6.77 \mathrm{mmol} / 1$ and $3.5 \%$ of the heterozygotes had values under $6.77 \mathrm{mmol} / 1$. If this cholesterol concentration is used as a cut-off point $4.25 \%$ of cases would be misdiagnosed.

\section{Introduction}

The risk of early death from coronary heart disease in men heterozygous for familial hypercholesterolaemia ${ }^{1}$ is about 10 times that of men in the general population whose serum cholesterol concentration exceeds $7 \cdot 8 \mathrm{mmol} / \mathrm{l}(300 \mathrm{mg} / 100 \mathrm{ml}){ }^{2}$ The risk of coronary heart disease in female heterozygotes is also increased, though it is substantially lower than that for men. As many as a quarter of the survivors of myocardial infarction may have serum cholesterol levels raised over 2 standard deviations above the mean (age and sex adjusted), and of the hypercholesterolaemic survivors a quarter are likely to be heterozygous for familial hypercholesterolaemia. ${ }^{3}$

The children of patients with familial hypercholesterolaemia have a chance of carrying the single mutant gene of 1 in 2 . Thus the early detection and treatment of affected children may contribute to preventing premature coronary heart disease. ${ }^{4}$ In adults familial hypercholesterolaemia may be difficult to diagnose as neither serum total cholesterol values nor low density lipoprotein (LDL) cholesterol concentrations distinguish heterozygotes from those whose lipid values are in the upper $5 \%$ of the range found in the general population. Additional evidence, such as the presence of tendinous xanthomata in the patient or the detection of a hypercholesterolaemic relative, is necessary. It may be easier to diagnose the heterozygous state in childhood because the environmental influences that determine the serum cholesterol concentration will have operated for a shorter time and because other causes of hypercholesterolaemia are less common than in adults.

\section{Institute of Child Health, London WC1}

J V LEONARD, MB, MRCP, lecturer in child health

A G L WHITELAW, MB, MRCP, research fellow, department of child health

$\mathrm{O} \mathrm{H}$ WOLFF, MD, FRCP, professor of child health

J K LLOYD, MD, FRCP, professor of child health (present address: St George's Hospital Medical School, London SW 17)

MRC Clinical Genetics Unit, Institute of Child Health, London WC1 J SLACK, DM, MRCP, consultant and honorary senior lecturer the distribution of serum cholesterol values in British children who had at least one first-degree relative with presumed familial hypercholesterolaemia to assess the confidence with which this estimation can be used to make the diagnosis.

\section{Subjects and methods}

Altogether 134 children, aged 1-16 years, from 57 kinships were seen at the Hospital for Sick Children, Great Ormond Street, London, because at least one first-degree relative was considered to have familial hypercholesterolaemia.

We defined hypercholesterolaemia in adults as a serum cholesterol value over 2 standard deviations above the mean expected for the age. ${ }^{3}$ The first-degree relative with hypercholesterolaemia was an adult in 49 kinships and a child in eight. Fifty-one of these index patients were alive when the family was first seen. Four of the remaining index patients had died between the ages of 19 and 30 , and the age at death of the other two was unknown. In these six families at least one other first-degree relative was also found to be hypercholesterolaemic. Of 43 surviving adult index patients 23 had clinical evidence of coronary heart disease and three of these died later.

Six of the eight children who were index patients were detected either during investigation for other conditions (4), or in epidemiological studies (2). The other two index children, one of whom had the homozygous form of the disease, presented with tuberose xanthomata. In 11 families the index patient or a first-degree relative had tendinous xanthomata as well as hypercholesterolaemia. In 28 kinships the index patient had two or more first-degree relatives with documented hypercholesterolaemia and in 18 kinships one first-degree relative was known to be hypercholesterolaemic.

Whenever possible blood samples were collected from the children after an overnight fast; occasionally non-fasting samples were used to estimate total serum cholesterol. Serum cholesterol was measured by a semi-automated ferric chloride technique ${ }^{6}$ in the Institute of Child Health. When serial blood samples were taken for cholesterol measurement before the start of treatment the mean value was used in the calculations. Serum LDL was isolated by density gradient ultracentrifugation. ${ }^{7}$

For some families who lived long distances from our hospital the initial cholesterol level was determined locally and only children with abnormal or borderline values were referred to us. Eight children are missing from the analysis because they were considered to be unaffected.

The maximum likelihood technique was used to fit a one- and twopopulation model to the data. ${ }^{8}$ Unpaired $t$ test and regression analysis were performed by standard methods. ${ }^{9}$

\section{Results}

The distribution of the total serum cholesterol values of the 134 children (the 8 index children were excluded) appeared to be bimodal (fig 1). The two peaks represent the affected (heterozygotes) and unaffected children. The peak for the unaffected children was smaller because of the method of selection and referral, which tended to exclude families in whom all the children were considered to be unaffected. The distribution was positively skewed and in all subsequent calculations a logarithmic transformation was applied. In this small sample with a wide range no trend with age was observed, but there was the expected sex difference. ${ }^{10}$ The boys' mean value was $6.75 \mathrm{mmol} / 1(261 \mathrm{mg} / 100 \mathrm{ml})$ and that of the girls $7.8 \mathrm{mmol} / 1$ (301 


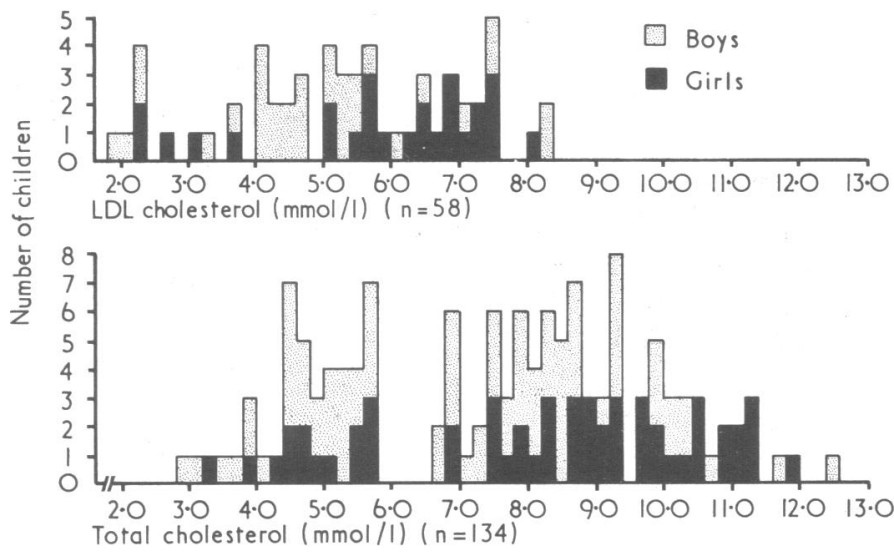

FIG 1-Serum total cholesterol and low density lipoprotein cholesterol (LDL cholesterol) values of children from kinships with familial hypercholesterolaemia.

Conversion: SI to traditional units-Cholesterol: $1 \mathrm{mmol} / 1 \approx 38.6 \mathrm{mg} / 100 \mathrm{ml}$.

$\mathrm{mg} / 100 \mathrm{ml})(t=-2.55 ; \mathrm{P}<0.02)$. Ideally we would have analysed the data for the two sexes separately, but the numbers were too small.

The results of the maximum likelihood estimates confirmed that for total serum cholesterol a two-population model (fig 2) was more likely than a single Gaussian curve $\left(y^{2}=18.99 ; \mathrm{DF}=3 ; \mathrm{P}<0.0005\right)$.

The estimated mean in the unaffected population was $4.9 \mathrm{mmol} / 1$ $(188 \mathrm{mg} / 100 \mathrm{ml})$ and that in the heterozygotes $8.9 \mathrm{mmol} / 1(343 \mathrm{mg} / 100$ $\mathrm{ml})$. The $\pm 2-\mathrm{SD}$ range for the unaffected population was $3 \cdot 2-7 \cdot 3$ $\mathrm{mmol} / \mathrm{l}(125-281 \mathrm{mg} / 100 \mathrm{ml})$ and for the heterozygotes $6 \cdot 6-12 \cdot 0$ $\mathrm{mmol} / 1$ (254-464 mg/100 ml). The estimated proportion of individuals in the lower mode was $35.5 \%$ of the total sample, which would mean that about 48 children were probably unaffected. As we knew that ascertainment was incomplete, we assumed in subsequent calculations that the proportions in each population were equal since familial hypercholesterolaemia is dominantly inherited. ${ }^{11} 12$ The two curves thus calculated intersected at $6.77 \mathrm{mmol} / 1(261 \mathrm{mg} / 100 \mathrm{ml})$. Five per cent of unaffected children would be expected to have values over $6 \cdot 77$ $\mathrm{mmol} / 1$ and $3.5 \%$ of heterozygote children would be expected to have values lower than $6.77 \mathrm{mmol} / \mathrm{l}$. At the point of intersection a minimum

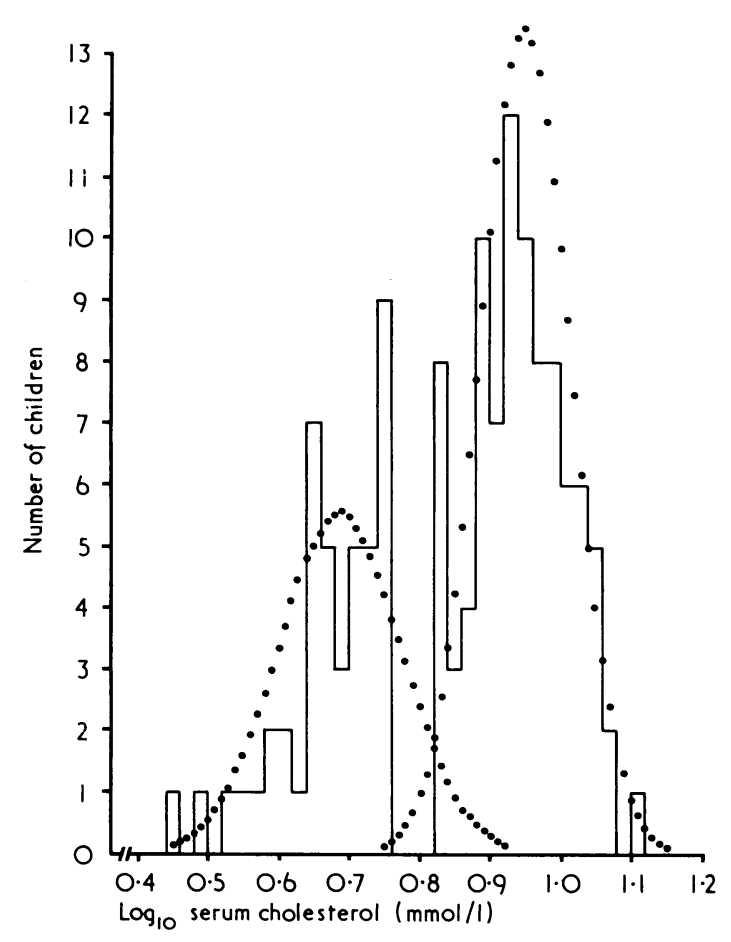

FIG 2-Distribution of serum total cholesterol, transformed to the logarithm, and the fitted curves of the heterozygotes and unaffected children.
$(4.25 \%)$ of the total population (unaffected plus heterozygotes) would be misclassified. The proportions that would be misclassified at other cholesterol concentrations are shown in the table.

Proportions of heterozygotes and unaffected children who would have been misclassified at various cholesterol concentrations. Numbers in each population were assumed to be equal

\begin{tabular}{|c|c|c|c|c|c|c|c|c|}
\hline Cholesterol $(\mathrm{mmol} / \mathrm{l})$ : & $6 \cdot 0$ & $6 \cdot 2$ & $6 \cdot 4$ & $6 \cdot 6$ & $6 \cdot 8$ & $7 \cdot 0$ & $7 \cdot 2$ & $7 \cdot 4$ \\
\hline $\begin{array}{l}\text { Unaffected children } \\
\text { Heterozygotes }\end{array}$ & $\begin{array}{r}14 \cdot 8 \\
0.5\end{array}$ & $\begin{array}{r}11.3 \\
0.8\end{array}$ & $\begin{array}{l}8 \cdot 6 \\
1.5\end{array}$ & $\begin{array}{l}6 \cdot 4 \\
2 \cdot 4\end{array}$ & $\begin{array}{l}4 \cdot 8 \\
3 \cdot 8\end{array}$ & $\begin{array}{l}3 \cdot 5 \\
5 \cdot 6\end{array}$ & $\begin{array}{l}2 \cdot 5 \\
8 \cdot 1\end{array}$ & $\begin{array}{r}1 \cdot 8 \\
11 \cdot 2\end{array}$ \\
\hline
\end{tabular}

Serum LDL cholesterol was measured in 58 children (fig 1). The values correlated well with serum total cholesterol values $(r=0.93)$, but a bimodal distribution was not evident, possibly because of the small sample. Nevertheless, our data provided no evidence that for this age group LDL cholesterol was a better discriminator than serum total cholesterol.

\section{Discussion}

Familial hypercholesterolaemia is usually diagnosed on the basis of high serum total or LDL cholesterol concentrations in the patients and first-degree relatives. Although it may be easy to distinguish between affected and unaffected people in one kinship, ${ }^{13}$ borderline results often occur, and in small families the diagnosis may be difficult to make. ${ }^{14}$

Kwiterovich et al ${ }^{12}$ studied the distribution of serum total and LDL cholesterol concentrations in the offspring of 90 matings in which one parent was considered to have familial hypercholesterolaemia. Using the maximum likelihood technique, they found that the serum cholesterol values fell into two overlapping populations. At a cholesterol concentration of $6.09 \mathrm{mmol} / 1(235 \mathrm{mg} / 100 \mathrm{ml})$, which was the point of minimum misclassification, $13.7^{\circ}$ of the children would have been misdiagnosed. LDL cholesterol was found to be a better discriminator, but still $8.45^{\circ}{ }_{0}$ of children would have been incorrectly classified. In the children we studied the serum cholesterol values of the two populations overlapped less. The discrimination between heterozygotes and unaffected children in our series was not improved by estimating LDL cholesterol in the small number of children studied.

The difference between our findings and those of Kwiterovich et $\mathrm{al}^{12}$ may have been due to differences in the criteria by which familial hypercholesterolaemia was diagnosed in the index patient and to differences in environmental factors. In our families the evidence for familial hypercholesterolaemia was least secure for children with only one first-degree relative with hypercholesterolaemia. When the children from these kinships were omitted and the analysis was repeated the estimated means and variances changed only slightly (mean in unaffected children $4.62 \mathrm{mmol} / 1(178 \mathrm{mg} / 100 \mathrm{ml})$; mean in heterozygotes 8.90 $\mathrm{mmol} / \mathrm{l}(343 \mathrm{mg} / 100 \mathrm{ml}))$. This finding suggests that the cholesterol values among children with only one affected firstdegree relative did not differ significantly from values in children in whom the diagnosis was more certain.

Our findings suggest that when the total serum cholesterol concentration is in the range of $6 \cdot 5-7 \cdot 0 \mathrm{mmol} / 1(251-270 \mathrm{mg} / 100$ $\mathrm{ml}$ ) the diagnosis of familial hypercholesterolaemia cannot be made or excluded with complete confidence. We do not consider it justifiable to treat such children without at least obtaining serial estimations that show raised cholesterol concentrations over a reasonable period of time. The diagnosis is likely to be more difficult to establish in boys than in girls because of the lower cholesterol concentrations in the boys. Unfortunately it is the men who carry the greater risk of coronary heart disease ${ }^{1}$ and in whom it is important to make an early diagnosis in order to start treatment. Alternative methods of diagnosing familial hypercholesterolaemia are needed. Possibly the abnormality of 
the LDL receptor sites ${ }^{15}$ may provide the basis for a test with greater discriminating capacity than the determination of total serum cholesterol or LDL cholesterol.

We thank Miss Audrey Fosbrooke for performing the estimations and $\mathrm{Mr} \mathrm{A} \mathrm{J} \mathrm{Westlake} \mathrm{for} \mathrm{his} \mathrm{help} \mathrm{with} \mathrm{the} \mathrm{statistics} \mathrm{and} \mathrm{computing.}$

Requests for reprints should be addressed to Dr J V Leonard, Department of Child Health, Institute of Child Health, London WC1.

\section{References}

1 Slack, J, Lancet, 1969, 2, 1380.

2 Slack, J, fournal of the Royal College of Physicians of London, 1974, 8, 115.

3 Patterson, D, and Slack, J, Lancet, 1972, 1, 393.

4 Lloyd, J K, Wolff, O H, Fournal of Atherosclerosis Research, 1969, 10, 135.
- West, R J, Fosbrooke, A S, and Lloyd, J K, Postgraduate Medical fournal, 1975, 51, 82.

6 Fosbrooke, A S, and Pringle, G A, Clinica Chimica Acta, 1970, 30, 47.

7 Cornwell, D G, et al, American fournal of Clinical Nutrition, 1961, 9, 24.

${ }^{8}$ Murphy, E A, and Bolling, D R, American fournal of Human Genetics, $1967,19,322$.

${ }^{9}$ Armitage, P, Statistical Methods in Medical Research. Oxford, Blackwell Scientific, 1971.

10 Lloyd, J K, in Recent Advances in Paediatrics, 5th edn, ed D Hull, chap 13, p 334. London, Churchill Livingstone, 1976.

${ }^{11}$ Nevin, N C, and Slack, J, fournal of Medical Genetics, 1969, 5, 9.

12 Kwiterovich, P O, Fredrickson, D S, and Levy, R I, fournal of Clinical Investigation, 1974, 53, 1237.

${ }^{13}$ Khachadurian, A K, American fournal of Medicine, 1964, 37, 402.

${ }^{14}$ Leonard, J V, et al, Archives of Disease in Childhood, 1976, 51, 842

${ }^{15}$ Brown, M S, and Goldstein, J L, New England fournal of Medicine, 1976, 294, 1386.

(Accepted 1 April 1977)

\title{
Fluctuations of serum and bile lipid concentrations during the menstrual cycle
}

\author{
T S LOW-BEER, A C B WICKS, K W HEATON, P DURRINGTON, J YEATES
}

\begin{abstract}
Summary
We measured fasting serum and bile lipid concentrations at three intervals during the normal menstrual cycles of 11 healthy women not taking oral contraceptives. In nine of them cholesterol saturation of bile, and therefore presumably the risk of developing gall stones, was higher nine days after midcycle than at the end of menstruation. This change in bile cholesterol saturation was preceded by a significant fall in serum lipid concentrations: during the nine days after mid-cycle serum triglyceride and cholesterol concentrations fell in nine and eight of the 11 women respectively. Changes in the composition of serum and biliary lipids during the menstrual cycle are presumably due to a direct effect of sex hormones on the liver.
\end{abstract}

\section{Introduction}

Women are more likely to develop gall stones than men. ${ }^{1}$ The gall stones commonly found in affluent societies are rich in cholesterol. ${ }^{2}$ There is much to suggest that this sex-related difference is partly due to sex hormones. For example-oral contraceptives encourage the oversaturation of bile with cholesterol $^{3}{ }^{4}$ and gall stones seem to be commoner in women taking oestrogens either as part of the contraceptive pill ${ }^{5}$ or for relief of post-menopausal symptoms. ${ }^{6}$ Pregnancy appears to

\footnotetext{
University Department of Medicine, Royal Infirmary, Bristol BS2 8HW

T S LOW-BEER, BM, MRCP, lecturer in medicine (present appointment: consultant physician and gastroenterologist Selly Oak Hospital, Birmingham B29 6JD)

A C B WICKS, MD, MRCP, research fellow

$\mathrm{K}$ W HEATON, MD, FRCP, consultant senior lecturer in medicine

$P$ DURRINGTON, MB, MRCP, senior house officer in medicine

J YEATES, technician
}

predispose to gall stones. ${ }^{1}$ Cholesterol saturation of both monkey and rat bile may be altered by changing sex-hormone concentrations in the blood. ${ }^{8-10}$

Blood concentrations of oestrogen and progestogen fluctuate considerably during the normal menstrual cycle. We thought that bile cholesterol saturation might also fluctuate, and consequently the risk of forming gall stones. We therefore decided to study biliary lipid composition during normal menstrual cycles, and in view of the relationship between serum and biliary lipids, ${ }^{11}$ and between serum lipids and sex hormones, ${ }^{12}$ we also measured fasting serum cholesterol and triglyceride concentrations.

\section{Subjects and methods}

Twelve healthy female volunteers aged $20-43$ years were accepted for these studies. All had a history of regular 26-30 day menstrual cycles and had not taken any hormone preparations for three months before the study. One woman had a cycle which was abnormally long for her so she was excluded.

Each woman was studied on three occasions during her menstrual cycle: the day after menstruation had ceased (usually the fifth or sixth day after starting), when oestrogen and progesterone concentrations are generally low; at mid-cycle (assessed as 14 days before the predicted date of menstruation), when oestrogen concentrations are normally at their highest; and eight to nine days later, at the expected progesterone peak. To ensure that the order of study did not influence the results, seven women began the study at the end of menstruation, and the other four at mid-cycle. On each of the three occasions bile and blood samples were collected after an overnight fast of nine hours. The women swallowed a duodenal tube, and 5-8 $\mathrm{ml}$ of bile was aspirated after intravenous pancreozymin injection (Boots Co Ltd). The aspirate was immediately divided into aliquots and stored at $-20^{\circ} \mathrm{C}$ for subsequent estimation of concentrations of cholesterol and phospholipid, total bile-salt content, the bile-salt composition, and the ratio of glycine to taurine conjugation. All samples from each subject were always analysed in the same batch.

Biliary cholesterol concentrations were assayed by gas-liquid chromatography, using a pure cholesterol standard. ${ }^{13}$ Phospholipid concentrations were measured by the method of $\mathrm{King}^{14}$ without prior lipid extraction. For total bile salts, the $3-\alpha$-hydroxysteroid dehydrogenase enzyme system was used. ${ }^{15}$ The relative concentrations of these three lipids were expressed as a cholesterol saturation index. ${ }^{16-18}$ The 